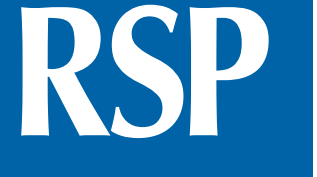

http://www.rsp.fsp.usp.br/
Revista de Saúde Pública

\title{
Latin American interventions in children and adolescents' sedentary behavior: a systematic review
}

\author{
Evelyn Helena Corgosinho Ribeiro' ${ }^{\text {ID , Paulo Henrique Guerra }}{ }^{1,11}$ (ID), Ana Carolina de Oliveira ${ }^{1, \text { III }}$ (iD, \\ Kelly Samara da Silva ${ }^{\mathrm{IV}}$ iD, Priscila Santosiv ${ }^{\mathrm{ID}}$, Rute Santos ${ }^{\mathrm{v}, \mathrm{v}, \mathrm{VII}}$ (iD, Anthony Okely ${ }^{\mathrm{VI}}$ iD, Alex \\ Antonio Florindol, III iD \\ ' Universidade de São Paulo. Grupo de Estudos e Pesquisas Epidemiológicas em Atividade Física e Saúde. São \\ Paulo, SP, Brasil \\ " Universidade Federal da Fronteira Sul. Chapecó, SC, Brasil \\ III Escola de Artes, Ciências e Humanidades da Universidade de São Paulo. São Paulo, SP, Brasil \\ iv Universidade Federal de Santa Catarina. Núcleo de Pesquisa em Atividade Física e Saúde. Florianópolis, SC, Brasil \\ $\checkmark$ Universidade do Porto. Centro de Investigação em Actividade Física, Saúde e Lazer. Porto, Portugal \\ vı Universidade Lusófona. Lisboa, Portugal \\ VII University of Wollongong. Early Start. Wollongong, Australia
}

\section{ABSTRACT}

OBJECTIVE: To identify and evaluate the effects of community-based interventions on the sedentary behavior (SB) of Latin American children and adolescents.

METHODS: A systematic review on community-based trials to reduce and/or control SB in Latin American countries (Prospero: CRD42017072157). Five databases (PubMed, Web of Science, Scopus, SciELO and Lilacs) and a reference lists were searched.

RESULTS: Ten intervention studies met the eligibility criteria and composed the descriptive synthesis. These studies were conducted in Brazil $(n=5)$, Mexico $(n=3)$, Ecuador $(n=1)$ and Colombia $(n=1)$. Most interventions were implemented in schools $(n=8)$ by educational components, such as meetings, lessons, and seminars, on health-related subjects ( $\mathrm{n}=6)$. Only two studies adopted specific strategies to reduce/control SB; others focused on increasing physical activity and/or improving diet. Only one study used an accelerometer to measure SB. Seven studies investigated recreational screen time. Eight studies showed statistically significant effects on SB reduction (80\%).

CONCLUSIONS: Latin America community-based interventions reduced children and adolescents' SB. Further studies should: define SB as a primary outcome and implement strategies to reduce such behaviour; focus in different SBs and settings, other than recreational screen time or at-home sitting time; and use objective tools together with questionnaires to measure sedentary behaviour in.

DESCRIPTORS: Child. Adolescent. Sedentary Behavior. Evaluation of the Efficacy-Effectiveness of Interventions. Systematic Review.

Copyright: This is an open-access article distributed under the terms of the Creative Commons Attribution License, which permits unrestricted use, distribution, and reproduction in any medium, provided that the original author

and source are credited.

How to cite: Ribeiro EHC, Guerra $\mathrm{PH}$, Oliveira AC, Silva KS, Santos AA. Latin American interventions in children and adolescents' sedentary behavior: a systematic review. Rev Saude Publica. 2020;54:59. 


\section{INTRODUCTION}

High levels of sedentary behavior (SB) -activities in a seated or reclining position requiring low energy expenditure ${ }^{1}$ are associated with cardiovascular diseases, diabetes and premature mortality risk ${ }^{2}$. A study that analyzed over one million people reported that high activity level (60 to 75 minutes per day) attenuate, but does not eliminate, the increased mortality risk associated with high TV-viewing time ( $\geq 3$ hours per day) ${ }^{2}$. This type of SB is very common among children and adolescents ${ }^{3}$.

SB in childhood and adolescence is related to overweight and obesity, insufficient levels of physical activity (PA), unhealthy food consumption, and poor academic performance and perceptions of well-being ${ }^{4-7}$. A systematic review reported that SB also plays a role in weight gain from childhood to adulthood ${ }^{8}$.

Among children and adolescents, SB is usually assessed by self-reported recreational screen time (e.g., TV-viewing, using computer, tablet or smartphone for non-school work, or playing electronic games) or objective measurements (e.g., accelerometers as ActiGraph and ActivPAL) ${ }^{9}$, which provide information on total SB time but does not discriminate the type of activity and its context. The contexts in which young people are usually sedentary are little explored, such as sitting time at home, at school, and during transportation ${ }^{3}$.

Guidelines from several countries state that children and adolescents should spend less than two hours a day in recreational screen time ${ }^{10,11}$, as well as limit sedentary transport, sitting time, and indoors time during the day ${ }^{10}$. Yet, studies conducted in high-income countries showed that youth spend from two to four hours a day in recreational screen time and are sedentary from five to ten hours daily3.

In Latin America, over $50 \%$ of children and adolescents do not follow the recommendation of < 2 hours a day using electronic media for recreational purposes ${ }^{12-15}$. Higher levels of recreational screen time appear to be more prevalent among girls, adolescents, urban area residents, and less active individuals ${ }^{13-16}$. Tracking shows that SB increases with age, and that childhood and adolescence lifestyles are maintained during adulthood ${ }^{13,17-19}$. Such findings indicate that preventive efforts need to commence as soon as possible to educate and support children in maintaining healthy levels of recreational screen time and overall sitting time.

Intervention studies are key to identify effective strategies in reducing high SB levels. Regarding children and adolescents, most interventions are implemented in schools and communities. Systematic reviews have shown the potential of strategies in reducing recreational screen time among children and adolescents, such as classroom sessions, educational newsletter, homework assignments for parents, counseling practices, and TV-viewing time reduction ${ }^{21}$. However, most of these studies were conducted in highincome countries ${ }^{20,21}$, hampering the generalization of their findings into low-, middle- and upper-middle- income countries, as they differ in potential correlates of SB and acquire less available resources to support potential interventions ${ }^{22}$.

Reducing SB is a global goal and Latin America low-, middle- and upper-middle-income countries, as Brazil and Mexico, are testing strategies to achieve it, but the results of these interventions have not yet been summarized. This study aimed to identify and evaluate the effects of community-based interventions to reduce or control SB among children and/or adolescents in Latin American countries.

\section{METHODS}

\section{Study Design}

This systematic literature review followed the Prisma (Preferred Reporting Items for Systematic Reviews and Meta-Analyses) protocol and was registered in Prospero (CRD42017072157). 
The following databases were searched: PubMed, Web of Science, Scopus, SciELO and Lilacs. Systematic searches combined keywords for type of study, SB and population: (((intervention[Text Word] ) OR strategy[Text Word])) AND $((((($ sedentary behavior[Text Word]) OR sitting time[Text Word]) OR screen time[Text Word]) OR television[Text Word]) OR computer[Text Word]) OR videogame[Text Word]). Activated filters: Clinical Trial; Controlled Clinical Trial; Pragmatic Clinical Trial; Randomized Controlled Trial; Humans; Child: birth-18 years. The document detailing all strategies applied can be requested by email to the corresponding author. Searches were filtered and/or performed in English, Portuguese and Spanish. To avoid potential losses, articles that were assessed by its fulltexts had their reference lists checked (manual search). Searches in Google Scholar were also performed.

\section{Selection process and data extraction}

Inclusion criteria were: (i) intervention studies (experimental and quasi-experimental); (ii) implemented in community settings (e.g.: school, public clubs/parks, primary health care centers); (iii) in which primary or secondary objective was reducing SB; (iv) conducted with children and adolescents ( $<18$ years old); (v) in Latin American countries and; (vi) published until May 2019.

Three researchers, organized in two pairs (EHCR-ACMO; EHCR-PCS), assessed titles, abstracts, full texts and data collection. A senior reviewer (PHG) solved doubts and disagreements.

Data were collected in a structured spreadsheet, organized as follows: (i) sample characterization, study site (city/country) and primary object; (ii) study type, number and type of settings (school, church, home), duration and description of the intervention and control group; (iii) SB assessment method and number of individuals included in the analyzes; and (iv) description of SB results. When available, study protocols were consulted.

Two reviewers independently assessed the risk of bias using an adapted version of the Effective Public Health Practice Project (EPHPP) instrument ${ }^{23,24}$. This instrument analyzes important domains of intervention studies (selection, study design, confounders, blinding of assessors, data collection methods, withdrawals and drop-outs, analyses) and ranks the information as low, moderate and high risk of bias. The adjusted EPHPP can be requested by contacting the corresponding author.

\section{RESULTS}

Figure 1 shows the flowchart. Of the 4,148 potential references, 709 duplicates were removed and 3,439 selected for title and abstract screening. After screening, 27 studies were referred for full text assessment, of which 17 were removed (reasons: outcome $[\mathrm{n}=3]$, study design $[\mathrm{n}=3]$, country [n=10], incomplete data $[\mathrm{n}=1]$ ) and 10 selected for the descriptive syntheses. All included studies were cluster randomized controlled trials.

Interventions were implemented in Brazil $(n=5)^{25-29}$, Mexico $(n=3)^{30-32}$, Ecuador $(n=1)^{33}$, and Colombia $(\mathrm{n}=1)^{34}$. Most studies involved adolescents and were focused more on girls than boys $^{25-27,33}$. Five studies had SB as primary objective ${ }^{25,28,32-34}$ (Table 1).

\section{Description of the interventions}

Most interventions were school-based $(\mathrm{n}=8)^{25-28,30,32-34}$ and their lengths ranged from five days to 28 months. Five studies lasted at least six months $s^{25,26,30,32,33}$. Most studies $(\mathrm{n}=9)$ allocated participants into control and intervention groups. Rauber et al. $(2018)^{29}$ allocated into the intervention group participants who answered to advertisements on a regional television channel. Other study applied the same protocol of the intervention group to participants allocated at baseline to the control group, due to the benefits of the intervention ${ }^{30}$. One 


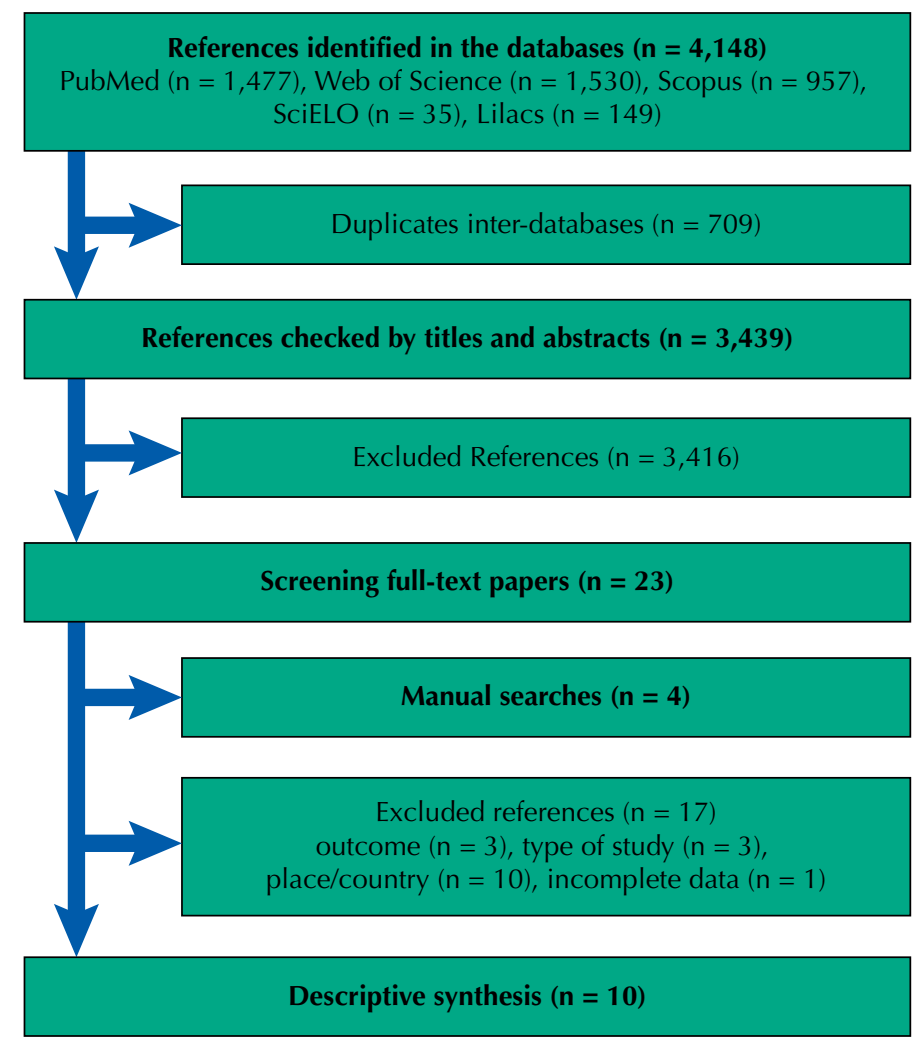

Figure 1. Systematic review flowchart.

Table 1. Descriptive characteristics of included studies.

\begin{tabular}{|c|c|c|c|c|c|}
\hline Reference & Program & Location (city/country) & $\begin{array}{l}\text { Mean age } \\
\text { (years) }\end{array}$ & $\begin{array}{l}\% \text { Females in } \\
\text { sample }\end{array}$ & $\begin{array}{l}\text { Primary objective of } \\
\text { the manuscript }\end{array}$ \\
\hline Colín-Ramírez et al. ${ }^{32}$ & RESCATE & Mexico City/Mexico & 9.4 & 48 & $\mathrm{PA}$ and Screen time \\
\hline Bacardi-Gascon et al..$^{30}$ & --- & Tijuana/Mexico & 8.5 & 49 & $\begin{array}{l}\text { BMI, PA and Food } \\
\text { Consumption }\end{array}$ \\
\hline Hardman et al. ${ }^{25}$ & Saúde na Boa & $\begin{array}{c}\text { Recife and } \\
\text { Florianopolis/Brazil }\end{array}$ & 18.4 & 56 & Screen time \\
\hline Martínez-Andrade et al. ${ }^{31}$ & Creciendo Sanos & Mexico City/Mexico & 3.4 & 47 & Obesity, PA and Diet \\
\hline Andrade et al. ${ }^{33}$ & ACTIVITAL & Cuenca/Ecuador & 12.8 & 68 & Screen time \\
\hline Leme et al. ${ }^{26}$ & Healthy Habits, Healthy Girls Brazil & Sao Paulo/Brazil & 16.1 & 100 & BMI \\
\hline Guimarães et al..$^{27}$ & --- & Campinas/Brazil & 16.5 & 75 & $\begin{array}{c}\text { PA and Cardiovascular } \\
\text { Risk Factors }\end{array}$ \\
\hline Bandeira et al. ${ }^{28}$ & Fortaleça sua Saúde & Fortaleza/Brazil & $11-17$ & 49 & Screen time \\
\hline Gutiérrez-Martínez et al. ${ }^{34}$ & $\begin{array}{c}\text { Estudio Internacional de Obesidad } \\
\text { Infantil, Estilos de Vida Y Medio } \\
\text { Ambiente (ISCOLE) }\end{array}$ & Bogota/Colombia & 10.5 & 57.5 & PA, SB and Adiposity \\
\hline Rauber et al. ${ }^{29}$ & HEPchild & Federal District/Brazil & $9-11$ & 62.5 & PA and Diet \\
\hline
\end{tabular}

$\mathrm{PA}=$ Physical Activity; $\mathrm{BMI}=$ Body Mass Index; $\mathrm{SB}=$ Sedentary Behavior

study measured SB by an accelerometer (GT3x+, ActiGraph) ${ }^{34}$, but the others applied questionnaires. Recreational screen time was the most investigated behavior (television, computer and videogame) $)^{25,26,28,30-33}$. In five studies, over $70 \%$ of participants (intervention and control group) completed the intervention ${ }^{26,28-30,33}$. Six studies performed their analyses following intention-to-treat principles ${ }^{25,26,30,31,33,34}$.

Educational components (meetings/lessons/seminars on health-related subjects) $(\mathrm{n}=7)^{26-30,32,33}$ and parents involvement $(\mathrm{n}=7)^{26,28-32,34}$ were the most applied strategies, followed by information (posters, newsletters, guidelines) $(\mathrm{n}=4)^{25,26,28,33}$ and extra physical 
Table 2. Interventions' General Characteristics.

\begin{tabular}{|c|c|c|c|c|c|c|c|c|c|}
\hline & Setting & Population & $\begin{array}{l}\text { Intervention } \\
\text { (months) }\end{array}$ & $\begin{array}{l}\text { Follow-up } \\
\text { (months) }\end{array}$ & $\begin{array}{l}\text { Methods of } \\
\text { measurement }\end{array}$ & $\begin{array}{l}\text { Assessed } \\
\text { Behaviors }\end{array}$ & $\begin{array}{l}\text { Sample } \\
\text { INT/CN }\end{array}$ & $\begin{array}{c}\text { Adherence } \\
\text { to protocol } \\
(\%)\end{array}$ & $\begin{array}{c}\text { ITT } \\
\text { analysis }\end{array}$ \\
\hline Colín-Ramírez et al. ${ }^{32}$ & School & Children & 12 & - & Questionnaire & Screen time & $245 / 253$ & 39.6 & No \\
\hline Bacardi-Gascon et al. ${ }^{30}$ & School & Children & 6 & 18 & Questionnaire & $\begin{array}{l}\text { Sitting/Screen } \\
\text { time }\end{array}$ & $280 / 252$ & 91.4 & Yes \\
\hline Hardman et al..$^{25,35,36}$ & School & Adolescents & 9 & - & Questionnaire & Screen time & $1059 / 1096$ & 44.8 & Yes \\
\hline Martínez-Andrade et al. ${ }^{31}$ & $\begin{array}{l}\text { Primary } \\
\text { Care } \\
\text { Clinics }\end{array}$ & $\begin{array}{l}\text { Children } \\
\text { (aged < 5) }\end{array}$ & 1.5 & 6 & Questionnaire & Screen time & $168 / 138$ & 64.9 & Yes \\
\hline Andrade et al. ${ }^{33,37}$ & School & Adolescents & 28 & - & Questionnaire & Screen time & $686 / 684$ & 79.7 & Yes \\
\hline Leme et al. ${ }^{26,38}$ & School & Adolescents & 6 & - & Questionnaire & $\begin{array}{l}\text { Computer/TV- } \\
\text { viewing }\end{array}$ & $142 / 107$ & 78.2 & Yes \\
\hline Guimarães et al..$^{27}$ & School & Adolescents & 3 & - & Questionnaire & $\begin{array}{l}\text { Sedentary } \\
\text { activities }\end{array}$ & $49 / 65$ & 53.1 & No \\
\hline Bandeira et al. ${ }^{28}$ & School & Adolescents & 3 & - & Questionnaire & Screen time & 1182 & 91.8 & No \\
\hline Gutiérrez-Martínez et al. ${ }^{34}$ & School & Children & 2.5 & - & $\begin{array}{c}\text { ActGraph } \\
\text { Gt3x+ }\end{array}$ & $\begin{array}{c}\text { SB } \\
(<25 \text { counts })\end{array}$ & $120 / 68$ & 65 & Yes \\
\hline Rauber et al. ${ }^{29}$ & Camp & $\begin{array}{l}\text { Children/ } \\
\text { Adolescents }\end{array}$ & 0.17 & 3 & Questionnaire & $\begin{array}{c}\text { Sedentary } \\
\text { leisure activities }\end{array}$ & 24 & 83 & No \\
\hline
\end{tabular}

INT=intervention; $\mathrm{CON}=$ control; $\mathrm{SB}=$ Sedentary Behaviour; Screen=television, computer and video game time; ITT=intention-to-treat.

education/PA sessions $(\mathrm{n}=5)^{26-29,34}$ (Table 3). In Martinez-Andrade et al. (2014) ${ }^{31}$, the intervention protocol boiled down to workshops with parents to modify their children PA behavior and dietary habits (aged from 2 to 5). The least applied strategies were: sending healthy messages to mobile phones $(n=2)^{26,34}$, providing exercise breaks in the classroom $(\mathrm{n}=1)^{3}$, and offering PA/sports events on weekends $(\mathrm{n}=1)^{25}$.

Schools promoted environmental modification by building bike racks ${ }^{25}$ and a walking trail ${ }^{33}$ and buying simple sports equipment for Physical Education classes ${ }^{25}$. (Table 3)

All interventions applied strategies to increase PA, and seven also focused on improving diet. Three studies proposed specific strategies to reduce SB: 1) a textbook for teachers and a workbook for adolescents, containing topics related to PA and screen time behavior (i.e. being active for at least $60 \mathrm{~min} /$ day and watching television for $<2$ hours a day), to be used on classes ${ }^{33}$;2) recommendations, handed to parents, including decreasing SB-activities time, like TV-viewing, using a computer, or playing videogames ${ }^{32}$; 3) pamphlets on screen time and health for both students and parents ${ }^{28}$. Four studies relied in professionals and students of both Physical Education/Activity and Nutrition for implementing the intervention strategies ${ }^{26,27,29,30}$.

\section{Results for Sedentary Behavior}

Eight interventions reported a positive effect in total SB or recreational screen time reduction ${ }^{26-30,32-34}$. Three effectively reduced the mean time spent in screen based activities to minutes per day (Table 4). One reduced the proportion of adolescents involved in recreational screen time for $\geq 2$ hours per day (TV: boys $=-8.9 \%$; girls $=-7.2 \%)^{28}$. The effect size for total SB ranged from -298.9 to -177.1 min/week, and -22.3 to -21.2 min/day (Table 4).

Andrade et al. (2015) ${ }^{33}$ observed that the intervention group showed smaller increases in screen time compared to the control group for the mean total on a weekend day (intervention: 88.1; control: 112.3 minutes a day) and for the proportion of adolescents with screen time behaviors of $>3$ hours a day (intervention: 17.4\%; control: 22.7\%) after 18 months. Changes were not maintained after 28 months.

Hardman et al. (2014) ${ }^{25}$ observed the benefit of the program Saúde na Boa on the proportion of adolescents in the intervention group exposed to videogame/computer on weekend days 


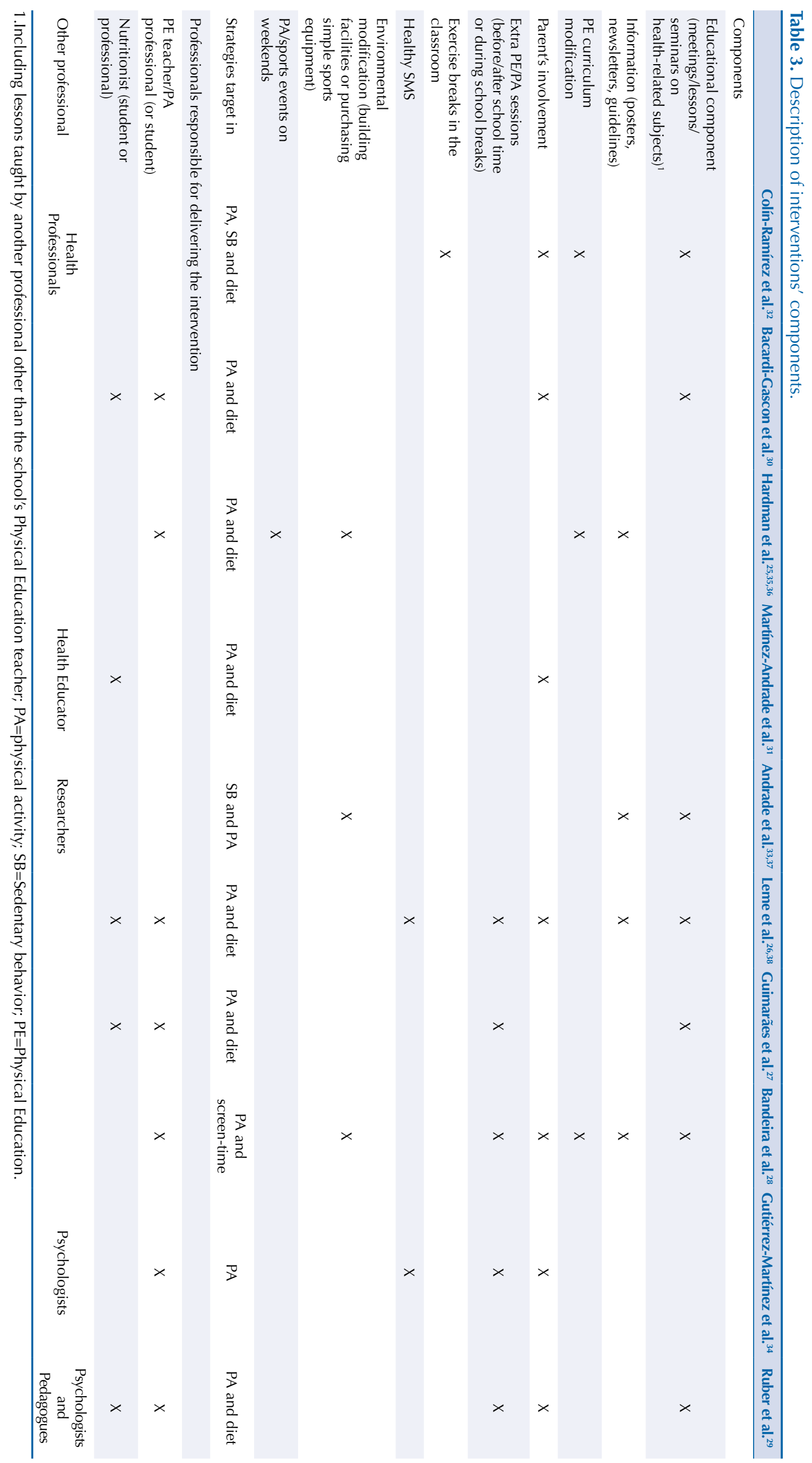


Table 4. Interventions' results

\begin{tabular}{|c|c|c|}
\hline Sedentary time & Effect size & Effect \\
\hline Martínez-Andrade et al. ${ }^{31}$ : no effect on SB. & $\begin{array}{l}\text { Mean difference of screen time } \\
-1.6(95 \% \mathrm{Cl}:-4.4-1.1)\end{array}$ & $\mathrm{NE}$ \\
\hline $\begin{array}{l}\text { Andrade et al. }{ }^{33}: 18 \text { months - the intervention group lower } \\
\text { increased total screen time on a weekend day }(\beta=-25.9 \mathrm{~min} / \text { day; } \\
\mathrm{p}=0.03) \text { and in the proportion of adolescents exposed to screen } \\
\text { time for }>180 \mathrm{~min} / \text { day; } 28 \text { months }- \text { greater increases in total } \\
\text { screen time on a weekday }(\beta=21.4 \mathrm{~min} / \text { day; } p=0.03 \text { ) were } \\
\text { observed among adolescents from the intervention group. }\end{array}$ & $\begin{array}{c}\text { Mean difference of screen time on } \\
\text { a weekday } \\
21.2 \mathrm{~min} / \text { day (SE :13.3) }\end{array}$ & $\mathrm{P}$ \\
\hline
\end{tabular}

Leme et al. ${ }^{26}$ : the intervention group reduced total sedentary activities on weekends $(-0.92 \mathrm{hrs} /$ day; $\mathrm{p}=0.01)$ compared to the control group.

Guimarães et al. ${ }^{27}$ : the intervention group reduced the total sedentary time (5652.1; $\mathrm{sd}=241.4$ to $5641.0 ; \mathrm{sd}=244.7 \mathrm{~min} /$ week; $\mathrm{p}=0.04$ ) and daily sedentary time (1589.22; $\mathrm{sd}=76.4$ to 1556.0 ; $\mathrm{sd}=73.7 \mathrm{~min} /$ day; $\mathrm{p}=0.01$ ) and presented lower mean compared to control group $(6333.7 ; \mathrm{sd}=177.2 \mathrm{~min} /$ week; $\mathrm{p}=0.04$ and 1697.16; $\mathrm{sd}=55.3 \mathrm{~min} /$ day; $\mathrm{p}=0.01$ ).

Gutiérrez-Martínez et al. ${ }^{34}$ : the intervention group reduced SB in $11.5(\mathrm{EE}=8.8$; MARA+SMS) and in $15.8(\mathrm{EE}=10.05$; MARA) differently from the control group, which has increased SB in $10.9(\mathrm{EE}=9.07 ; \mathrm{p}=0.003) \mathrm{min} /$ day .

Rauber et al. ${ }^{29}$ : participants reduced the time spent in sedentary leisure activities by $177 \mathrm{~min} /$ weekdays $(p=0.004)$ and by $41 \mathrm{~min} /$ weekends $(p=0.001)$.

Mean difference of total SB $-298.9 \mathrm{~min} /$ week (SE: 424.4) Mean difference for screen time $-55.5 \mathrm{~min} /$ day (SE: 406.8)

Mean difference of total SB $-22.3 \mathrm{~min} /$ day $(\mathrm{SE}: 17.9)$

Sitting time

Bacardi-Gascon et al. ${ }^{30}$ : reduced from $9.94(\mathrm{sd}=2.39$ ) to 9.45 $(\mathrm{sd}=1.91) \mathrm{hrs} / \mathrm{day}$

TV-viewing

Colín-Ramírez et al. ${ }^{32}$ : had no effect on TV time.

Mean difference of SB

$-177.1 \mathrm{~min} /$ weekdays

$-41.1 \mathrm{~min} /$ weekends

Mean difference of sitting time

$-0.49 \mathrm{~min} /$ day (SE :0.1)

Percentage of children with at least

1 hour a day of TV time $-4 \%$

Bacardi-Gascon et al. ${ }^{30}$ : reduced from $1.84(\mathrm{sd}=1.17)$ to 1.69 $(\mathrm{sd}=0.90) \mathrm{hrs} /$ day $(\mathrm{p}=0.02)$

Andrade et al. ${ }^{33}$ : 18 months - the intervention group lower increased TV-viewing on a weekday $(\beta=-15.7 \mathrm{~min} /$ day; $p=0.003)$ and a weekend day $(\beta=-18.9 \mathrm{~min} /$ day; $\mathrm{p}=0.005) ; 28$ months Greater increases in TV-viewing $(\beta=13.1 \mathrm{~min} /$ day; $p=0.02)$ were observed among adolescents from the intervention group.

Bandeira et al. ${ }^{28}$ : the intervention group reduced the time of TV to less than $2 \mathrm{hrs} /$ day (boys: $-8.9 \% ; \mathrm{p}=0.005$; girls: $-7.2 \%$; $\mathrm{p}=0.032$ ). Boys in the intervention group had a greater chance to reduce TV use to $<2 \mathrm{hrs} /$ day $(\mathrm{OR}=2.86 ; \mathrm{p}=0.037)$ compared to boys in the control group.

Video game/computer

Colín-Ramírez et al. ${ }^{32}$ : 6 months - no effect; 12 months - the intervention group significantly reduced the amount of hours playing video games $(23 \%$ to $13 \%$; $p=0.001)$ among children who spent more than $3 \mathrm{hrs}$ /day involved in this activity at baseline. This reduction was not observed in the control group (22\% to $20 \%$ ).

Hardman et al. ${ }^{25}$ : the proportion of adolescents exposured to video game/computer on weekend days for $>2 \mathrm{hrs} /$ day was greater in the control group than in the intervention group $(29.8 \%$ vs. $35.6 \%$; $p=0.004)$. After adjusting for potential confounding factors, results were not maintained.

Leme et al. ${ }^{26}$ : the intervention group reduced computer time $(-0.63 \mathrm{hrs} /$ day; $\mathrm{p}=0.02)$ compared to the control group.

Bandeira et al. ${ }^{28}$ : girls in the intervention group reduced the time of computer/video game to less than $2 \mathrm{hrs} /$ day $(-11.03 \% ; \mathrm{p}=0.0 .002)$. Girls and adolescents aged from 11 to 13 in the intervention group had a greater chance to reduce computer/video game use to $<2 \mathrm{hrs} /$ day (girls: $\mathrm{OR}=3.34 ; \mathrm{p}<0.001 ; 11$ to 13 years old: $\mathrm{OR}=3.08 ; \mathrm{p}=0.011$ ) compared to the control group.

$\mathrm{NE}=$ no effect; $\mathrm{P}=$ positive effect - result statistically significant
Exposures to total screen time $>2 \mathrm{hrs} /$ day

Week: $\mathrm{OR}=0.94$

(95\% $\mathrm{Cl}: 0.72-1.22)$

Weekend: $\mathrm{OR}=1.05$

(95\%Cl:0.76-1.43)

Odds ratio for reducing the use of screens $<2 \mathrm{hrs} /$ day

Boys: $\mathrm{OR}=3.79(95 \% \mathrm{Cl}: 0.5-29.7)$

Girls: OR $=2.73(95 \% \mathrm{Cl}: 0.5-15.1)$ 


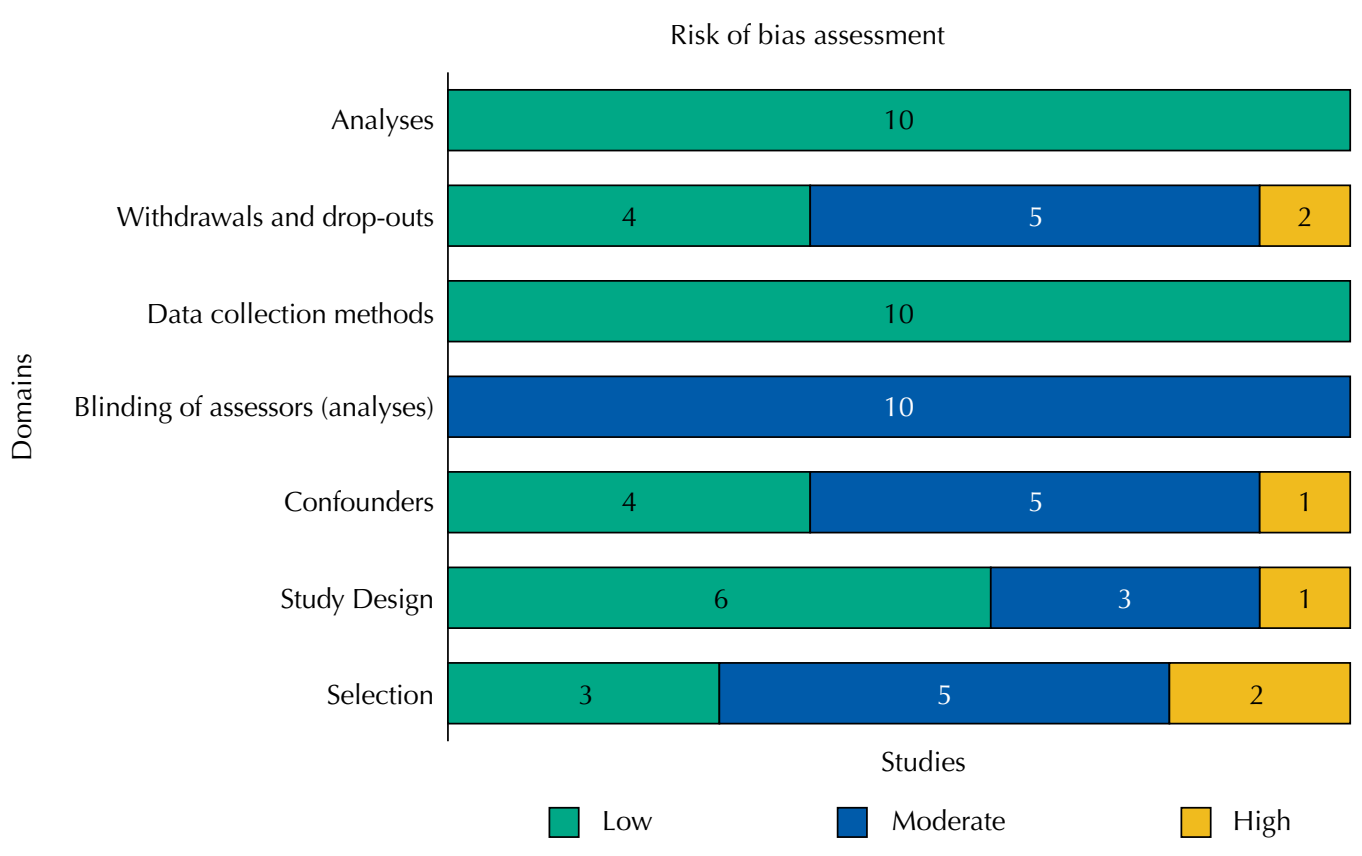

Figure 2. Risk of bias

for $>2$ hours compared to the control group (intervention: 29.8\%; control: $35.6 \%$ ), which was not maintained after adjusting for potential confounding factors.

\section{Risk of Bias}

Most studies included in the syntheses were classified as low risk of bias in the domains: study design $(\mathrm{n}=5)^{25,26,30,31,33}$, data collection methods $(\mathrm{n}=10)$, analyses $(\mathrm{n}=10)$, and the use of intention-to-treat $(n=6)^{25,26,30,31,33,34}$ approaches. A higher proportion of studies were scored as moderate risk of bias in the domains of selection ${ }^{25-27,33,34}$, blinding of assessors ${ }^{25-28,30-34}$, and withdrawals and drop-outs ${ }^{26,27,31,33,34}$. For the domain of confounders, four studies presented low risk of bias ${ }^{28,30,31,33}$, four presented moderate ${ }^{26,27,32,34}$ and one high risk ${ }^{25}$. Other studies scored high risk of bias for the domains of withdrawals and drop-outs ${ }^{25,29}$, and selection ${ }^{31}$.

\section{DISCUSSION}

Based on the results of ten community-based trials, the descriptive syntheses showed that the most effective community-based interventions were implemented in schools, adopted educational strategies, such as meetings, lessons or seminars on health-related subjects, targeted increasing PA, and were applied by a Physical Education/PA professional.

We found that effective interventions targeted changes in multiple health behaviors, corroborating Grieken et al. (2012) $)^{39}$, which reported no difference in the positive effects of interventions of single or multiple health behavior on SB. In this review, the combination of strategies to increase $\mathrm{PA}$, reduce $\mathrm{SB}$, and improve diet were beneficial for $\mathrm{SB}$.

Only a few studies aimed specifically at reducing SB and applied strategies focused on $\mathrm{it}^{25,32,33}$. The main strategies were: (1) recommending for parents a more active lifestyle and decreasing SB time spent on television, computer or videogame ${ }^{32}$; and (2) discussing SB and its guidelines in the classroom by a school teacher guided by a didactic material ${ }^{33}$.

Colín-Ramírez et al (2010) ${ }^{32}$ implemented the first strategy, recommending for parents a more active lifestyle, and, after 12 months, the intervention group reduced the daily number of hours playing videogames. The second strategy, discussing SB in the classroom, was 
still effective after 18 months-follow-up, but not after 28 months. This result is consistent with the systematic review and meta-analysis of Maniccia et al. $(2012)^{40}$ of interventions targeting reducing children's screen time, in which the authors observed larger statistically significant effects during the intervention period than during follow-up ${ }^{40}$.

Screen time was the most prevalent type of SB investigated, even among interventions implemented at schools, where children and adolescents spend a great part of their day sitting and a relatively small amount of time using electronic media for recreational purposes.

Schools are an ideal setting for interventions promoting healthier behaviors and reducing time spent in sedentary activities, as they allow interdisciplinary and multisectoral actions and facilitate parents' involvement, favoring changes in family's behavior. Schools also enable beneficial environmental modifications, such as building bike racks and walking trail, and providing sports equipment to be use during the children's breaks ${ }^{25,33}$.

Previous reviews ${ }^{20,21}$ observed that interventions effectively controlled and/or reduced recreational screen time (the most prevalent type of SB within young people) ${ }^{3}$ among children and adolescents even in low-, middle- and upper-middle-income countries ${ }^{12-15}$.

In our review, studies evaluated recreational screen time and other types of SB using a questionnaire. Although questionnaires are the most common tool applied to measure SB, they might not be the most accurate for relying solely on participants' or their parents' memories to report activities done over a period of time. Yet, objective measurements express a general SB measure, precluding the identification of the contexts in which this behavior has been adopted. A single study within our syntheses applied an objective measurement and not a questionnaire ${ }^{33}$.

Although at-home recreational screen time is above the recommended ${ }^{10,11}$, children and adolescents also spend a lot of time in SB in others settings, especially at school, while attending classess or during the breaks.

Effective interventions included the following educational strategies: school board and teachers meeting, to create a supportive environment for health behaviors; parents education sessions ${ }^{30}$; and textbooks for teachers and workbooks for adolescents on PA and $\mathrm{SB}$, discussed over class. ${ }^{33}$ The most prevalent strategies applied were distributing guidelines and newsletters on nutrition and $\mathrm{PA},{ }^{26}$ and arranging instructional meetings ${ }^{27}$.

Our results showed that seven studies in Latin America adopted family involvement ${ }^{26,28-32,34}$, which was effective when combined with educational strategies, information, exercise breaks in the classroom, extra PA sessions and health messages ${ }^{26,29,32}$. Biddle et al. (2014) ${ }^{41}$ review, on interventions to reduce SB in young people, also identified family involvement as an effective strategy. Although some authors observed a more favorable trend in interventions with children younger than six years, we found only one study within this age group ${ }^{31}$ and its intervention was focused on PA and dietary habits, not affecting SB.

Schmidt et al. (2012) ${ }^{20}$ and Wu et al. (2016) ${ }^{21}$ reported that electronic monitor devices, contingent feedback, clinical counseling, and classroom-based health curriculum were effective in reducing screen time among children and adolescents. In both of these reviews, all but one study, conducted in Mexico, were in high-income countries and, as aforementioned, SB determinants and correlates differ according to country's culture and resources $^{22,33,42,43}$. This finding reinforces the need to test whether intervention strategies to reduce SB in children and adolescents in high-income countries are also relevant in low-, middle- and middle-upper income countries.

In Latin America, most of the effective interventions lasted at least six months, ${ }^{26,30,32,33}$ similar to studies conducted in high-income countries ${ }^{21}$ and in line with the minimum length recommended to promote behavior change ${ }^{44}$. 
The main limitation of our review is lack of searches in non-indexed Latin American journals and grey literature, which might have excluded studies that reported no intervention effect. Moreover, our evidence comprises studies from a small number of Latin America countries $(n=4)$.

Our investigation was the first to summarize the effect and characteristics of Latin America interventions to control/reduce SB among children and adolescents. Another strength is the risk of bias assessment. However, as the high risk of bias in dropout and selection rates could play a role in the non-effect of some interventions ${ }^{23,29}$, results should be interpreted with caution.

Our findings indicate gaps and a need for further studies that (i) define SB as a primary objective and implement strategies to reduce it; (ii) target sedentary activities and settings other than at-home screen time and time spent sitting in the classroom; (ii) use objective tools together with questionnaires to measure SB, informing a more reliable SB time and which settings and types of sedentary activity are more common among young people; (iv) conduct interventions in Latin America countries other than Brazil, Mexico, Ecuador, and Colombia.

Most Latin America interventions did not define SB as a primary objective or applied strategies specific to it. Yet, they effectively reduced SB, mainly recreational screen time, among children and adolescents. Effective interventions were conducted at school and often applied educational and informative strategies, as meetings, seminars, workshops, and distribution of guidelines and newsletters.

These results are important for public managers to plan actions to reduce SB among children and adolescents considering contexts and activities other than at-home leisure time, as young people are also sedentary at school and transportation.

\section{REFERENCES}

1. Pate RR, $\mathrm{O}^{\prime}$ Neill JR, Lobelo F. The evolving definition of "sedentary". Exerc Sport Sci Rev. 2008;36(4):173-8. https://doi.org/10.1097/JES.0b013e3181877d1a

2. Ekelund U, Steene-Johannessen J, Brown WJ, Fagerland MW, Owen N, Powell KE, et al. Does physical activity attenuate, or even eliminate, the detrimental association of sitting time with mortality? A harmonised meta-analysis of data from more than 1 million men and women. Lancet. 2016;388(10051):1302-10. https://doi.org/10.1016/S0140-6736(16)30370-1

3. Salmon J, Tremblay MS, Marshall SJ, Hume C. Health risks, correlates, and interventions to reduce sedentary behavior in young people. Am J Prev Med. 2011;41(2):197-206. https://doi.org/10.1016/j.amepre.2011.05.001

4. Matthews CE, Chen KY, Freedson PS, Buchowski MS, Beech BM, Pate RR, et al. Amount of time spent in sedentary behaviors in the United States, 2003-2004. Am J Epidemiol. 2008;167(7):87581. https://doi.org/10.1093/aje/kwm390

5. Foley LS, Maddison R, Jiang Y, Olds T, Ridley K. It's not just the television: survey analysis of sedentary behaviour in New Zealand young people. Int J Behav Nutr Phys Act. 2011;8(1):132. https://doi.org/10.1186/1479-5868-8-132

6. Mitchell JA, Pate RR, Beets MW, Nader PR. Time spent in sedentary behavior and changes in childhood BMI: a longitudinal study from ages 9 to 15 years. Int J Obes. 2013;37(1):54-60. https://doi.org/10.1038/ijo.2012.41

7. Downing KL, Hinkley T, Salmon J, Hnatiuk JA, Hesketh KD. Do the correlates of screen time and sedentary time differ in preschool children? BMC Public Health. 2017;17(1):285. https://doi.org/10.1186/s12889-017-4195-x

8. Thorp AA, Owen N, Neuhaus M, Dunstan DW. Sedentary behaviors and subsequent health outcomes in adults: a systematic review of longitudinal studies, 1996-2011. Am J Prev Med. 2011;41(2):207-15. https://doi.org/10.1016/j.amepre.2011.05.004

9. Tremblay MS, LeBlanc AG, Kho ME, Saunders TJ, Larouche R, Colley RC, et al. Systematic review of sedentary behaviour and health indicators in school-aged children and youth. Int J Behav Nutr Phys Act. 2011;8(1):98. https://doi.org/10.1186/1479-5868-8-98 
10. Tremblay MS, LeBlanc AG, Janssen I, Kho ME, Hicks A, Murumets K, et al. Canadian sedentary behaviour guidelines for children and youth. Appl Physiol Nutr Metab. 2011;36(1):59-64. https://doi.org/10.1139/H11-012

11. Council on Communication and Media. Children, adolescents, and the media. Pediatrics. 2013;132(5):958-61. https://doi.org/10.1542/peds.2013-2656

12. Ministério da Saúde (BR); Ministério do Planejamento, Orçamento e Gestão, Instituto Brasileiro de Geografia e Estatística. Pesquisa Nacional de Saúde do Escolar: 2015. Rio de Janeiro: IBGE; 2016.

13. Ferreira RW, Rombaldi AJ, Ricardo LIC, Hallal PC, Azevedo MR. Prevalence of sedentary behavior and its correlates among primary and secondary school students. Rev Paul Pediatr. 2016;34(1):56-63. https://doi.org/10.1016/j.rpped.2015.06.005

14. Aguilar-Farias N, Cortinez-O'Ryan A, Sadarangani KP, Von Oetinger A, Leppe J, Valladares M, et al. Results from Chile's 2016 Report Card on Physical Activity for Children and Youth. J Phys Act Health. 2016;13(11 Suppl 2):S117-23. https://doi.org/10.1123/jpah.2016-0314

15. Galaviz KI, Arroyo MA, González-Casanova I, Villalobos MFG, Jáuregui A, Ulloa EJ, et al. Results from Mexico's 2016 Report Card on Physical Activity for Children and Youth. J Phys Act Health. 2016;13(11 Suppl 2):S206-12. https://doi.org/10.1123/jpah.2016-0363

16. Menezes AS, Duarte MFS. Condições de vida, inatividade física e conduta sedentária de jovens nas áreas urbana e rural. Rev Bras Med Esporte. 2015;21(5):338-44. https://doi.org/1517-869220152105145322

17. Jones RA, Hinkley T, Okely AD, Salmon J. Tracking physical activity and sedentary behavior in childhood: a systematic review. Am J Prev Med. 2013;44(6):651-8. https://doi.org/10.1016/j.amepre.2013.03.001

18. Biddle SJH, Pearson N, Ross GM, Braithwaite R. Tracking of sedentary behaviours of young people: a systematic review. Prev Med. 2010;51(5):345-51. https://doi.org/10.1016/j.ypmed.2010.07.018

19. Busschaert C, Cardon G, Van Cauwenberg J, Maes L, Van Damme J, Hublet A, et al. Tracking and predictors of screen time from early adolescence to early adulthood: a 10-year follow-up study. J Adolesc Health. 2015;56(4):440-8. https://doi.org/10.1016/j.jadohealth.2014.11.016

20. Schmidt ME, Haines J, O'Brien A, McDonald J, Price S, Sherry B, et al. Systematic review of effective strategies for reducing screen time among young children. Obesity (Silver Spring). 2012;20(7):1338-54. https://doi.org/10.1038/oby.2011.348

21. Wu L, Sun S, He Y, Jiang B. The effect of interventions targeting screen time reduction: a systematic review and meta-analysis. Medicine (Baltimore). 2016;95(27):e4029. https://doi.org/10.1097/MD.0000000000004029

22. Mielke GI, Brown WJ, Nunes BP, Silva ICM, Hallal PC. Socioeconomic correlates of sedentary behavior in adolescents: systematic review and meta-analysis. Sports Med. 2017;47(1):61-75. https://doi.org/10.1007/s40279-016-0555-4

23. Guerra PH, Nobre MRC, Silveira JAC, Taddei JAAC. School-based physical activity and nutritional education interventions on body mass index: a metaanalysis of randomised community trials - Project PANE. Prev Med. 2014;61:81-9. https://doi.org/10.1016/j.ypmed.2014.01.005

24. Thomas BH, Ciliska D, Dobbins M, Micucci S. A process for systematically reviewing the literature: providing the research evidence for public health nursing interventions. Worldviews Evid Based Nurs. 2004;1(3):176-84. https://doi.org/10.1111/j.1524-475X.2004.04006.x

25. Hardman CM, Barros MVG, Lopes AS, Lima RA, Bezerra J, Nahas MV. Efetividade de uma intervenção de base escolar sobre o tempo de tela em estudantes do ensino médio. Rev Bras Cineantropom Desempenho Hum. 2014;16 Supl 1:25-35. https://doi.org/10.5007/1980-0037.2014v16s1p25

26. Leme ACB, Lubans DR, Guerra PH, Dewar D, Toassa EC, Philippi ST. Preventing obesity among Brazilian adolescent girls: six-month outcomes of the Healthy Habits, Healthy Girls-Brazil school-based randomized controlled trial. Prev Med. 2016;86:77-83. https://doi.org/10.1016/j.ypmed.2016.01.020 
27. Guimarães RF, Silva MP, Martini MCS, Guerra-Júnior G, Gonçalves EM. The effects of an after-school intervention program on physical activity level, sedentary time, and cardiovascular risk factors in adolescents. Motriz. 2017;23 Spec №2:e101769. https://doi.org/10.1590/s1980-6574201700si0069

28. Bandeira AS, Silva KS, Sá SAM, Guerra PH, Mota J, Barbosa Filho VC. Effect of a multicomponent intervention on variables related to screen time in adolescents: a cluster-randomized controlled trial. Rev Bras Ativ Fis Saude. 2018;23:1-8. https://doi.org/10.12820/rbafs.12e0005

29. Rauber SB, Castro HO, Marinho A, Vicent JB, Ribeiro HL, Monteiro LZ, et al. Effects of a physical activity and nutritional intervention in overweight and obese children trhough an educational and recreational camp. Nutr Health. 2018;24(3):145-52. https://doi.org/10.1177/0260106018771519

30. Bacardí-Gascon M, Pérez-Morales ME, Jiménez-Cruz A. A six month randomized school intervention and an 18-month follow-up intervention to prevent childhood obesity in Mexican elementary schools. Nutr Hosp. 2012;27(3):755-62. https://doi.org/10.3305/nh.2012.27.3.5756

31. Martínez-Andrade GO, Cespedes EM, Rifas-Shiman SL, Romero-Quechol G, GonzálezUnzaga MA, Benítez-Trejo MA, et al. Feasibility and impact of Creciendo Sanos, a clinic-based pilot intervention to prevent obesity among preschool children in Mexico City. BMC Pediatr. 2014;14(1):77. https://doi.org/10.1186/1471-2431-14-77

32. Colin-Ramírez E, Castillo-Martínez L, Orea-Tejeda A, Vergara-Castañeda A, Keirns-Davis C, Villa-Romero A. Outcomes of a school-based intervention (RESCATE) to improve physical activity patterns in Mexican children aged 8-10 years. Health Educ Res. 2010;25(6):1042-9. https://doi.org/10.1093/her/cyq056

33. Andrade S, Verloigne M, Cardon G, Kolsteren P, Ochoa-Avilés A, Verstraeten R, et al. School-based intervention on healthy behaviour among Ecuadorian adolescents: effect of a cluster-randomized controlled trial on screen-time. BMC Public Health. 2015;15:942. https://doi.org/10.1186/s12889-015-2274-4

34. Gutiérrez-MartínezI L, Martínez RG, Gonzálezl SA, Bolívar MA, Estupiñanl OV, Sarmientol OL. Efectos de una estrategia de promoción de actividad física en escolares de Bogotá. Rev Saude Publica. 2018;52:79. https://doi.org/10.11606/S1518-8787.2018052017173

35. Nahas MV, Barros MVG, Assis MAA, Hallal PC, Florindo AA, Konrad L. Methods and participant characteristics of a randomized intervention to promote physical activity and healthy eating among Brazilian high school students: the Saude na Boa project. J Phys Act Health. 2009;6(2):153-62. https://doi.org/10.1123/jpah.6.2.153

36. Barros MVG, Nahas MV, Hallal PC, Farias Júnior JC, Florindo AA, Barros SSH. Effectiveness of a school-based intervention on physical activity for high school students in Brazil: the Saude na Boa project. J Phys Act Health. 2009;6(2):163-9. https://doi.org/10.1123/jpah.6.2.163

37. Andrade S, Lachat C, Ochoa-Aviles A, Verstraeten R, Huybregts L, Roberfroid D, et al. A school-based intervention improves physical fitness in Ecuadorian adolescents: a cluster-randomized controlled trial. Int J Behav Nutr Phys Act. 2014;11:153. https://doi.org/10.1186/s12966-014-0153-5

38. Leme ACB, Philippi ST. The "Healthy Habits, Healthy Girls" randomized controlled trial for girls: study design, protocol, and baseline results. Cad Saude Publica. 2015;31(7):1381-94. https://doi.org/10.1590/0102-311X00136014

39. Grieken A, Ezendam NPM, Paulis WD, Wouden JC, Raat H. Primary prevention of overweight in children and adolescents: a meta-analysis of the effectiveness of interventions aiming to decrease sedentary behaviour. Int J Behav Nutr Phys Act. 2012;9:61. https://doi.org/10.1186/1479-5868-9-61

40. Maniccia DM, Davison KK, Marshall SJ, Manganello JA, Dennison BA. A meta-analysis of interventions that target children's screen time for reduction. Pediatrics. 2011;128(1):e193-e210. https://doi.org/10.1542/peds.2010-2353

41. Biddle SJH, Petrolini I, Pearson N. Interventions designed to reduce sedentary behaviours in young people: a review of reviews. Br J Sports Med. 2014;48(3):182-6. https://doi.org/10.1136/bjsports-2013-093078

42. Stierlin AS, De Lepeleere S, Cardon G, Dargent-Molina P, Hoffmann B, Murphy MH, et al. A systematic review of determinants of sedentary behaviour in youth: a DEDIPAC-study. Int J Behav Nutr Phys Act. 2015;12:133. https://doi.org/10.1186/s12966-015-0291-4 
43. Guerra PH, Farias Júnior JC, Florindo AA. Sedentary behavior in Brazilian children and adolescents: a systematic review. Rev Saude Publica. 2016;50:9. https://doi.org/ 101590/S1518-8787.2016050006307

44. Prochaska JO, Velicer WF, Rossi JS, Goldstein MG, Marcus BH, Rakowski W, et al. Stages of change and decisional balance for 12 problem behaviors. Health Psychol. 1994;13(1):39-46. https://doi.org/10.1037//0278-6133.13.1.39

Funding: Alex Antonio Florindo is receiving a research fellowship from the Brazilian National Council for Scientific and Technological Development (CNPq) (grant 306635/2016-0).

Authors' Contribution: Study conception and approach: EHCR, PHG, AAF. Data collection: EHCR, PHG, ACO, PS. Data analysis and interpretation: EHCR, PHG. Study preparation and drafting: EHCR. Study critical review and final version approval: PHG, ACO, KSS, PS, RS, AO, AAF.

Conflict of interests: The authors declare no conflict of interest. 